\section{THE RADIUM INSTITUTE.}

THE Radium Institute, which was founded, at the suggestion of King Edward two years ago, by Sir Ernest Cassel and Viscount Ireagh, is to be formally opened on August 14th. This institution is devoted to the work of scientific research and to the skilled application of radium in the treatment of disease. On March 23rd the institute was inspected by His Majesty King George, who was accompanied by the Queen, and on July 10th it was again honoured with a visit by their Majesties Queen Alexandra and the Empress Marie Feodorovna of Russia. On the occasion of these visits demonstrations were given by the medical superintendent, Mr. A. E. Hayward Pinch, and by $\mathrm{Mr}$. W. Lester Alton, director of the chemico-physical laboratories. Quite recently Madame Curie has isolated radium, and describes it as a white metal oxidising

FIG. 1.

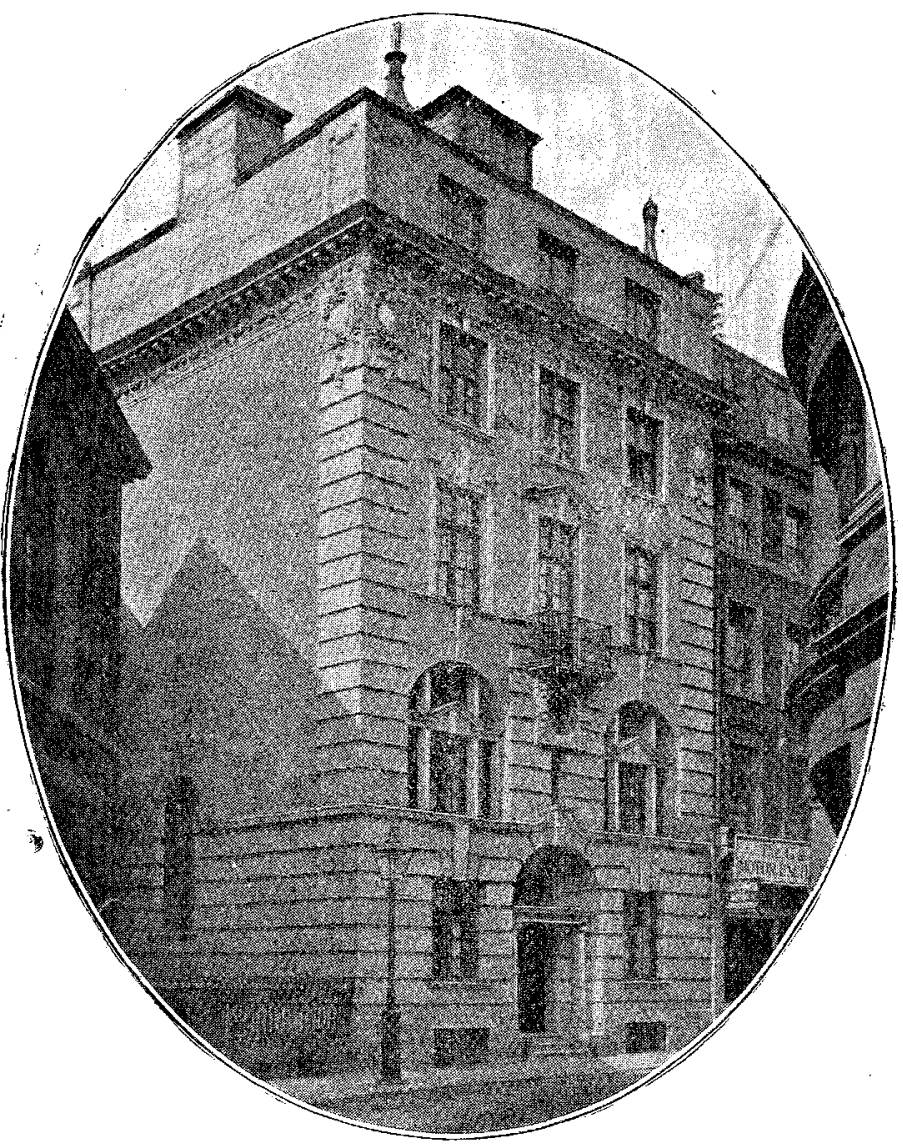

The facade of the Radium Institute.

in water, burning paper, turning black on exposure to air, and having the property of adhering firmly to iron. It is, however, with the compounds of radium that treatment is carried out, and we find on inquiry that the Radium Institute in London has stored in its building a larger supply of radium than is possessed by any other institution in the world; and so priceless is the commodity from a commercial point of view that we hesitate to estimate in terms of poucis, shillings, and pence the value of the precious element at 16, Riding House-street.

\section{The Radium Institute and the Medical Profession.}

A letter dated May 6th, 1911, from Sir Frederick Treves, chairman of committee, addressed to the medical superintendent, so exactly indicates the line of professional conduct to be followed in work at the institute that we freely paraphrase it. The letter stated in the first place that it was desirable that the medical superintendent should limit as far as possible his responsibilities in connexion with the patients who attended at the institute to indication of the specific treatment to be employed in each case, as well as the details of that treatment ; to ensuring that the treatment was carried out; and to declining to treat any unsuitable case. The diagnosis of the malady from which the patient is suffering will rest with the practitioner introducing the patient, and should the medical superintendent not agree with the diagnosis submitted he will discuss the matter with the practitioner; and should a third opinion be considered necessary, will call in, when the patient is a gratuitous one, a member of the honorary consulting staff. When diffculty as to diagnosis arises in the case of a paying patient, and a third opinion is needed, the practitioner will name the consultant unless he wishes to leave the nomination to the medical superintendent. But the patient must pay the fee of the consultant, no matter whether the consultation is held at the institute or at the consultant's house. In no case will the medical superintendent, acting on behalf of the institute, accept a fee for taking part in any consultation, and the honorary consulting staff, as a staff, are concerned only with the gratuitous patients treated at the institute, and no fee of any kind will be charged to such patients for any treatment carried out in the institute. For all special treaiment requiring, for example, a gynæcologist, the paying patient must pay such fees as are usually paid for like services. The medical superintendent's responsibility for the care of patients does not, of course, extend outside the institute.

Sir Frederick Treves's full letter is so simple and clear a document that it might well be framed and hung in the corridors of the institute, if only to convince everyone that the institute cannot be made use of to put fees into the pockets of any specially selected members of the medical profession.

Reguiations for Patients.

The following regulations for the admission of patients have been drawn up :-

Patients will only be treated at the Radium Institute in association with, and through the introduction of their medical adviser. At their first visit they must either be accompanied by their medical adviser or must bring with them his written statement of the case giving details of the treatment already employed. New patients will be seen on Tuesdays and Thursdays between the hours of 10 A.Mr. and 4 P.M., but the exact day and hour of any consultation must be arranged previously (by letter) with the medical superintendent, to whom all previously (by letter) with the med.

Medical practitioners are cordially inviter to be present during the treatment of their patients, and to assist in the same whenever practicable.

The medical superintendent on receiving a first inquiry from an individual for treatment posts off the following letter in reply :-

DEAR ...... - In reply to your letter of inquiry respecting the Radium Institute, I' beg to inform you that patuents can only be treated in Institute, 1 beg to inform you that patients can only be treated in I shall, therefore, be pleased to forward full particulars to your medical I shall, therefore, be pleased to forward full particulars to your medic
man if you will favour me with his name and address. - Yours truly, A. E. Harward Pirch, Medical Superintendent.

On receiving an answer giving the name of the medical practitioner the medical superintendent writes to that gentleman in the following terms:-

DEAR .....,.-In compliance with the request of your patient, $\mathbf{M}$...... I beg to forward you herewith particulars of the conditions under which patients are admitted to the Radium Institute for treatment, and the charges for the same.-Fours truly, A. F. HAYward Proch, Medical Superintendent.

The charges referred to are as follows :-

For first consultation at the Radium Institute, the patient being accompanied by his or her medical adviser, or bringing from such medical adviser a written history of the case... For treatment

1. When lesion is situated on external surface of body (a) With apparatus containing not more than 50 milligrammes of radium.

Per sitting

(b) With apparatus containing more than 50 milïgrammes of radium.

Per sitting

2. When lesion is situated $\dddot{\text { in }}$ cavity-e.g., läynx, $\ddot{\text { uterus, }}$ urethra, \&c.

$£$ s. $d$.

In regard to necessitous patients the following letter is sent to any such on application for free treatment:-

DEAR ......,-In reply to your letter of inquiry, I beg to inform you that necessitous patients are only admitted to free treatment at the Radium Institute if certified by their medical adviser to be suitable subjects for charity. If you will, therefore, be gond enough to ask your merlical man to fill up the enclosed certificate, and forward it to me, together with any notes with which he may furnish you, I will write fixing a day and hour for your attendance at the Radium Institute.-Yours faith ully,

A. E. Hayward Pirch, Medical Superintendent. 
FIG. 2.

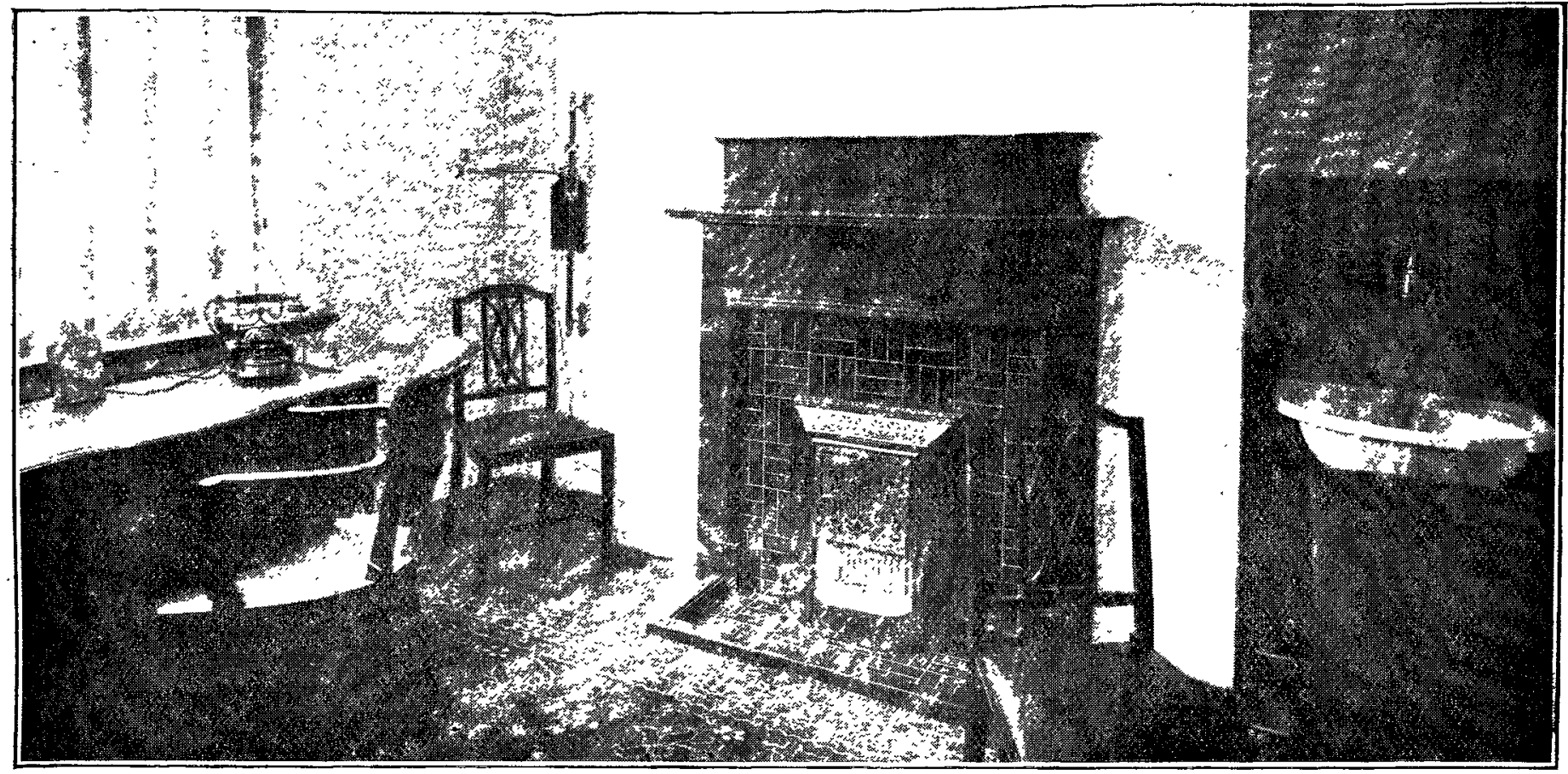

A consulting room, Radium Institute.

FIG. 3.

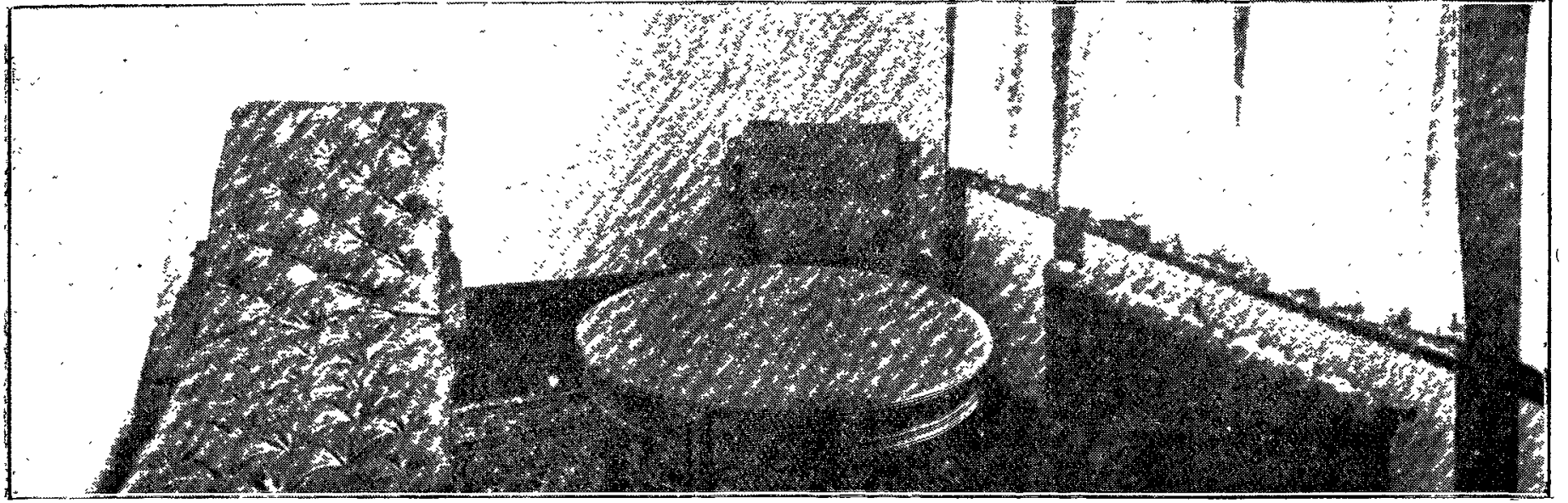

$\Lambda$ cubicle for treatment, Radium Institute.

FIG. 4.

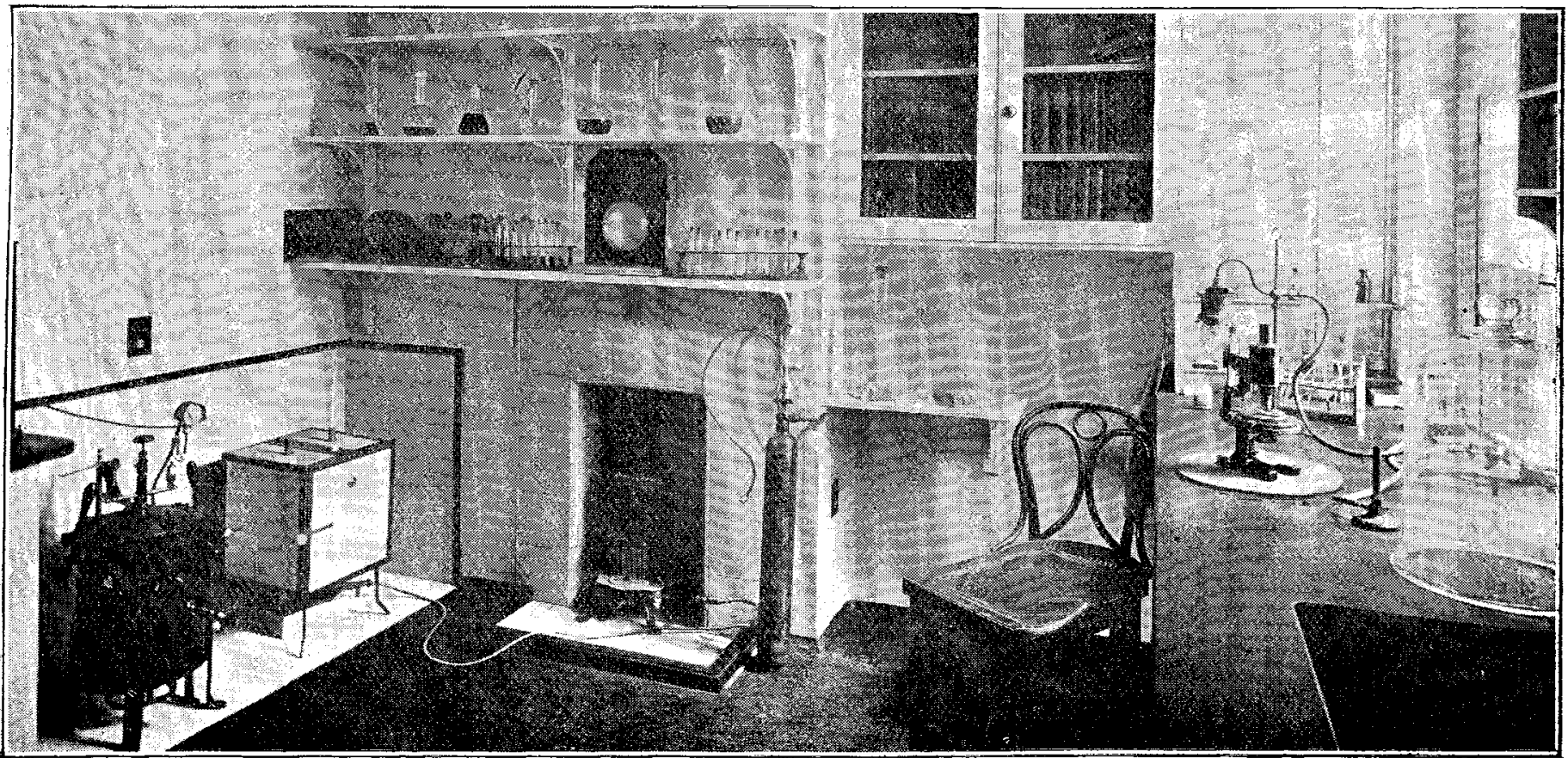

Pathological laboratory, Radium Institute. 
FIG. 5.

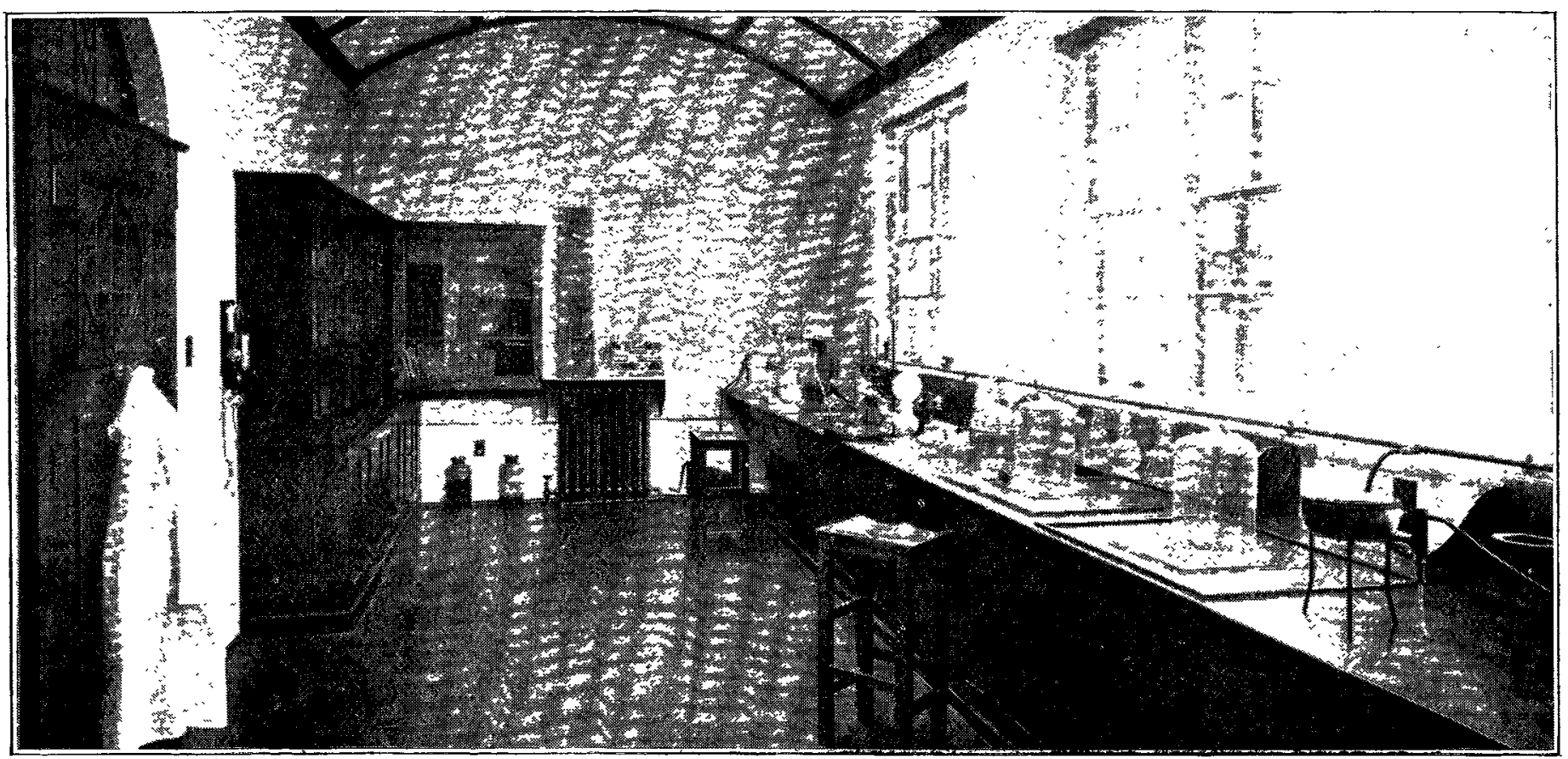

Chemico-physical laboratory, Radium Institute.

FIG. 6.

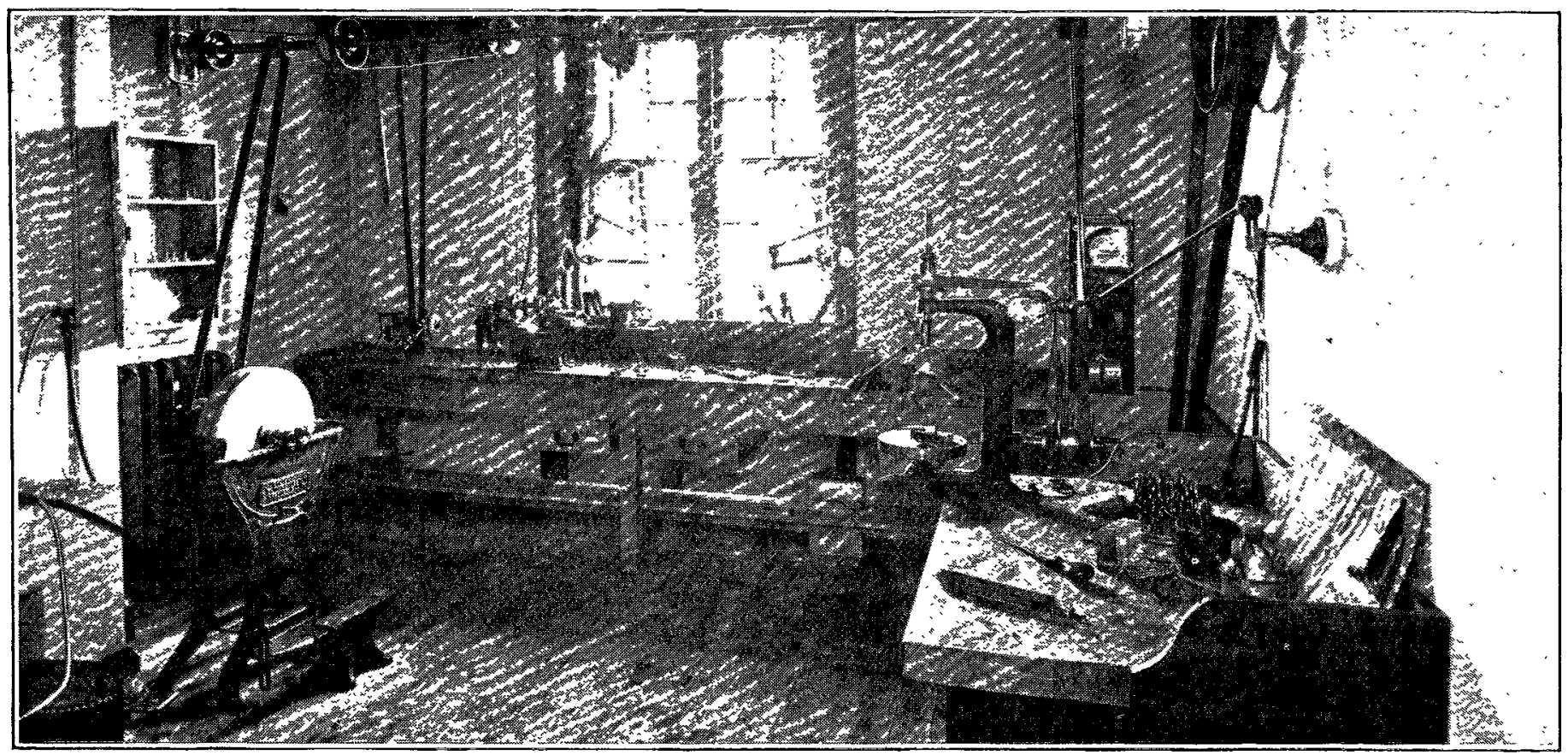

Engineer's shop, Radium Institute.

FIG. 7.

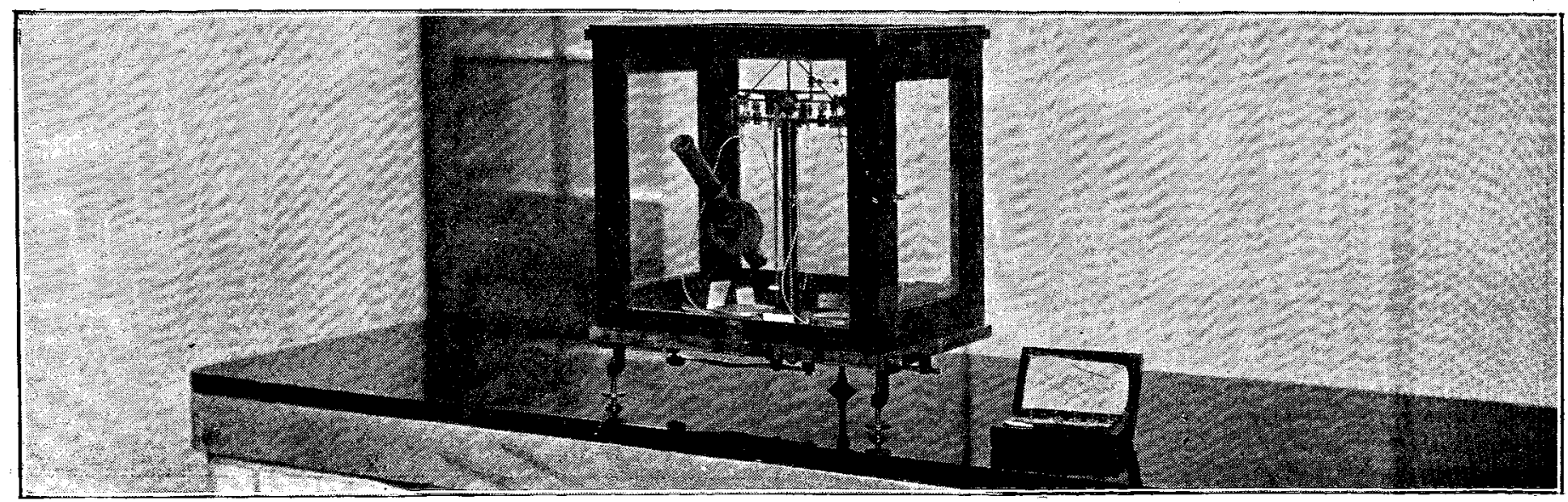


The certificate referred to runs thus :-

I HEREBY CERTIFY THAT

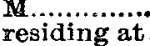

residing at.............

and that

rcumstances, and is to the best of my knowledge ...... is in necessitous for gratuitous treatment at the Radium Institute.

Name of Practitioner.

Qualification

Addres:

Date

Medical practitioners are cordially invited to be present during the treatment, of their patients, and to assist in the same whenever
practicable.

Medical men desiring information concerning the activity of specimens of radium salts can have the necessary information supplied from the chemico-physical laboratory of the institute at the following scale of fees for the examination of radium salts and the examination or preparation of radium applicators.

a) Measuring the amount of radium contained in specimens of radium salts

(b) Measuring the amount of radium contained in various forms of radium applicators

(c) Analysis of the rays emitted from various forms of $\ddot{\text { radium }}$ applicators

(d) Preparation of radium applicators. (To be made for medical men only.)

1. Circular or square dises

2. Cylindrical and special designs

(e) Examinations of water, minerals, and the like, for radioactivity

$£$ s.d. 220 sent to the institute for examination, \&c., it must be clearly understood that the examination of such specimens and apparatus is undertaken at the owner's risk, and that the institute cannot accept any liability with regard to the same.

Entering Riding House-street from Portland-place, the façade of the building of the institution presents itself as peculiarly suitable to the style of the architecture in its neighbourhood. Our illustration (Fig. 1) affords an excellent representation of the building.

On entering the institute we find on the ground floor the mecessary accommodation provided for the reception of patients both well-to-do as well as necessitous, and for the diagnosis of the cases presented. The first floor is fitted up for the treatment of patients, the second floor is devoted to scientific research, and the third floor is reserved for the workshops and the tools required to make the institution quite independent of all outside help in the matter of apparatus of all kinds, scientific and otherwise.

The consulting-rooms, one of which is shown in Fig. 2, are five in number on the ground floor, two of them being for well-to-do patients, two for the poor, and one for gynæcological examination. The equipment throughout the building is of the most aseptic character, and this characteristic of the place is well seen in the out-patient waiting-room, where the walls are tiled, the corners rounded, and the floor made of teak.

A further indication of the modern equipment of the institution is noticed in the fact that one of Tilley's chairs specially constructed for Killian's intubation method is already installed.

The first floor of the building is given up to treatment of patients, there being cubicles for treatment for the poor and for the rich. Fig. 3 indicates better than a description in words the style of one of these cubicles.

On the second floor ample accommodation is supplied for weientific research. Fig. 4 shows the pathological laboratory, and anyone acquainted with modern research would notice at once the latest pattern Zeiss microscope fitted with the most reliable appliances for dark-ground illumination; an up-to-date Minot microtome will not escape observation, nor a Leitz microtome freezing apparatus. On the same Bloor Mr. Alton, the director of the chemico-physical work, has his laboratory, and Fig. 5 indicates very clearly the excellent arrangements provided for this important branch of scientific study. The photographic room deserves a word of praise, and indeed it must have been fitted up absolutely regardless of expense.

On the third floor is a neat and well-equipped engineer's shop (Fig. 6), in which all the apparatus required for the work of the institution is manufactured.

The basement contains a room specially fitted for Mr. Alton's balance. This balance (Fig. 7) rests on a slab supported by two pillars, and these pillars pass through the foundations to such a depth that absence of any vibration is assured. Close to this room is the commudious safe for the storing of the radium.

The Radium Institute has for its patron His Majesty the King, and its presidents are the Viscount Ireagh and Sir Ernest Cassel. The Executive Committee is composed of Sir Frederick Treves, the Hon. W. E. Guinness. Mr. Felix Cassel, the Hon. J. Strutt, Sir Lauder Brunton, Sir William Ramsay, Sir Malcolm Morris, and Sir Joseph John Thomson. The honorary consulting staff consists of Mr. W. H. ClaytonGreene, Dr. Herbert French, Mr. W. H. H. Jessop, Dr. J. H. Sequeira, Dr. W. H. H. Tate, Mr. Herbert Tilley, and Mr. J. W. Thomson Walker. The technical assistant is Mr. John F. Holding, and the architect is Mr. T. P. Figgis, F.R.I.B.A.

\section{MEDICO - PSYCHOLOGICAL ASSOCIATION OF GREAT BRITAIN AND IRELAND.}

THE annual meeting of this association was held on July 13th and 14th at the Royal College of Physicians, Dublin, under the presidency of Dr. JOHN MACPHERSON.

Regret was expressed at the resignation of the veteran editors of the Journal of the association, Dr. H. Rayner and Dr. A. R. Urquhart, and Mr. H F. HAYES NewingToN (the treasurer) expressed the high appreciation by the association of their prolonged and able services.

Mr. HAYES NEWINGTON moved the adoption of the report of the Committee on the Medical Inspection of School Children and paid a high tribute to the good work done at Darenth.

The installation of the new President, Dr. William R. Dawson, followed a vote of thanks to the out-going President, Dr. Macpherson. Dr. Dawson presented, on behalf of the subscribers, a silver casket and an illuminated address to Dr. Edward Courtenay, on his retirement from the office of Inspector of Lunatic Asylums in Ireland.

Dr. Dawson, in his presidential address, discussed the geographical distribution of insanity in Ireland and compared it with that of other conditions, such as density of population, pauperism, and poverty, emigration, the death-rate (both general and tuberculous), criminality, and alcoholism, and illustrated his remarks with statistical diagrams. These showed that insanity prevailed in the agricultural counties, chiefly of the south and east, Ulster and Connanght being relatively free, and that pauperism had a similar distribution. It bore some, but not a marked, relation in local incidence to that of the emigration rate, criminality, and chronic alcoholism, but none, apparently, to density of population, rateable value of land, proportion of aged persons, death-rate, or drunkenness. The amount of insanity ascribed to alcohol in Ireland was small. Secondarily, it was found that pauperism and poverty were not necessarily alike in distribution. The President was hopeful for the future.

Dr. William Graham (Belfast) read a paper on Psychotherapy in Mental Disorder, a subject which, though little discussed here, had attracted widespread attention in France, Germany, and America, where men of international reputation had applied the methods with, it was said, singular success. The classical methods of psychotherapy were: (a) suggestion, waking and hypnotic ; $(b)$ therapeutic conversation; $(o)$ psycho-analysis ; $(d)$ occupation; and $(e)$ reeducation. (a) Suggestion as a therapeutic agent had been over-estimated; nevertheless, it was of value in certain types -e.g., alcoholism, sexual perversion, obsessions, phobias, multiple personality, and other forms of mental disturbance. (b) Therapeutic conversation (Dubois's method) consisted in explaining to the patient the origin and significance of his disorder so that the explanation became persuasion. This method was valuable in the less intractable types of disorder before the perverted idea had become too deeply rooted. But the patient was liable to get too dependent on the therapeutist, so that when removed from his influence a relapse was likely; and it was applicable only to a group of milder cases. (c) Psycho-analysis. This method (identified with the name of Frend) rested on the view that many disorders arose from the inability of the personality to assimilate certain experiences, such as those of a painful emotional character, and from the conflict thus set up between opposing groups of thought. The therapeutics consisted in making 